\title{
A Strong Convergence Theorem for Relatively Nonexpansive Mappings and Equilibrium Problems in Banach Spaces
}

\author{
Mei Yuan, ${ }^{1}$ Xi Li, ${ }^{2}$ Xue-song Li, ${ }^{2}$ and John J. Liu ${ }^{3}$ \\ ${ }^{1}$ Leshan College of Profession and Technology, Sichuan, Leshan 614000, China \\ ${ }^{2}$ Department of Mathematics, Sichuan University, Sichuan, Chengdu 610064, China \\ ${ }^{3}$ College of Business, City University of Hong Kong, Hong Kong \\ Correspondence should be addressed to Xue-song Li, xuesongli78@hotmail.com
}

Received 3 July 2012; Revised 24 August 2012; Accepted 24 August 2012

Academic Editor: Yeong-Cheng Liou

Copyright (C) 2012 Mei Yuan et al. This is an open access article distributed under the Creative Commons Attribution License, which permits unrestricted use, distribution, and reproduction in any medium, provided the original work is properly cited.

Relatively nonexpansive mappings and equilibrium problems are considered based on a shrinking projection method. Using properties of the generalized $f$-projection operator, a strong convergence theorem for relatively nonexpansive mappings and equilibrium problems is proved in Banach spaces under some suitable conditions.

\section{Introduction}

It is well known that metric projection operator in Hilbert and Banach spaces is widely used in different areas of mathematics such as functional analysis and numerical analysis, theory of optimization and approximation, and also for the problems of optimal control and operations research, nonlinear and stochastic programming and game theory.

Let $X$ be a real Banach space with its dual $X^{*}$, and let $K$ be a nonempty, closed, and convex subset of $X$. In 1994, Alber [1] introduced the generalized projections $\pi_{K}: X^{*} \rightarrow K$ and $\Pi_{K}: X \rightarrow K$ in uniformly convex and uniformly smooth Banach spaces based on the function $\phi(y, x)$ defined on p.3 and studied their properties in detail. In 2005, Li [2] extended the definition of the generalized projection operator from uniformly convex and uniformly smooth Banach spaces to reflexive Banach spaces and studied some properties of the generalized projection operator. Recently, Wu and Huang [3] introduced a new generalized $f$-projection operator in a Banach space. By making use of (2.5), they extended the definition of the generalized projection operators introduced by Abler [1] and proved some properties 
of the generalized $f$-projection operator. Wu and Huang [4] studied a relation between the generalized projection operator and the resolvent operator for the subdifferential of a proper convex and lower semicontinuous functional in reflexive and smooth Banach spaces (see [5-9]). Very recently, Li et al. [10] studied some properties of the generalized $f$-projection operator, and proved the strong convergence theorems for relatively nonexpansive mappings in Banach spaces.

On the other hand, equilibrium problem was introduced by Blum and Oettli [11], in 1994. It is a hot topic of intensive research efforts, because it has a great impact and influence in the development of several branches of pure and applied sciences. It has been shown that equilibrium problem theory provides a novel and unified treatment of a wide class of problems arisen in economics, finance, physics, image reconstruction, ecology, transportation, network, elasticity, and optimization problems. Numerous issues in physics, optimization, and economics reduce to finding a solution of equilibrium problem. Some methods have been proposed to solve the equilibrium problems (see, e.g, [12-14] and the references therein).

In this paper, motivated and inspired by the work mentioned above, we introduce a new hybrid projection algorithm based on the shrinking projection method for relatively nonexpansive mapping and equilibrium problem. Using the new algorithm, we prove a strong convergence theorem for relatively nonexpansive mappings and equilibrium problems in Banach spaces. The result presented in this paper extends and improves the main result of Li et al. [10].

\section{Preliminaries}

Let $X$ be a real Banach space with its dual $X^{*}$ and $R=(-\infty,+\infty)$. We denote the duality between $X$ and $X^{*}$ by $\left.\langle\cdot, \cdot\rangle\right\rangle$, and the norms of Banach space $X$ and $X^{*}$ by $\|\cdot\|_{X}$ and $\|\cdot\|_{X^{*}}$, respectively. A Banach space $X$ is said to be strictly convex if $\|(x+y) / 2\|<1$ for all $x, y \in X$ with $\|x\|=\|y\|=1$ and $x \neq y$. It is also said to be uniformly convex if $\lim _{n \rightarrow \infty}\left\|x_{n}-y_{n}\right\|=0$ for any two sequences $\left\{x_{n}\right\},\left\{y_{n}\right\}$ in $X$, such that $\left\|x_{n}\right\|=\left\|y_{n}\right\|=1$ and $\lim _{n \rightarrow \infty}\left\|\left(x_{n}+y_{n}\right) / 2\right\|=1$. The function

$$
\delta_{X}(\varepsilon)=\inf \left\{1-\frac{\|x+y\|}{2}:\|x\|=1,\|y\|=1,\|x-y\| \geq \varepsilon\right\}
$$

is called the modulus of convexity of $X$.

A Banach space $X$ is said to be smooth provided that $\lim _{t \rightarrow 0}(\|x+t y\|-\|x\|) / t$ exists for all $x, y \in X$ with $\|x\|=\|y\|=1$. It is also said to be uniformly smooth if the limit is attained uniformly for $\|x\|=\|y\|=1$. The function

$$
\rho_{X}(t)=\sup \left\{\frac{\|x+y\|+\|x-y\|}{2}-1:\|x\|=1,\|y\| \leq t\right\}
$$

is called the modulus of smoothness of $X$.

When $\left\{x_{n}\right\}$ is a sequence in $X$, we denote the strong convergence of $\left\{x_{n}\right\}$ with a cluster $x \in \mathrm{X}$ by $x_{n} \rightarrow x$ and the weak convergence of $\left\{x_{n}\right\}$ with a weak cluster $x \in \mathrm{X}$ by $x_{n} \rightarrow x$. A Banach space $X$ is said to have the Kadec-Klee property if a sequence $\left\{x_{n}\right\}$ of $X$ satisfies that 
$x_{n} \rightarrow x \in X$ and $\left\|x_{n}\right\| \rightarrow\|x\|$, then $x_{n} \rightarrow x$. It is known that if $X$ is uniformly convex, then $X$ has the Kadec-Klee property.

The normalized duality mapping $J$ from $X$ to $X^{*}$ is defined by

$$
J x=\left\{x^{*} \in X^{*}:\left\langle x, x^{*}\right\rangle=\|x\|^{2}=\left\|x^{*}\right\|^{2}\right\}
$$

for any $x \in X$. We list some properties of mapping $J$ as follows.

(i) If $X$ is a smooth Banach space (with Gâteaux differential norm), then $J$ is singlevalued and demicontinuous. If $X$ is a smooth reflexive Banach space, then $J$ is single-valued and hemicontinuous. If $X$ is a strongly smooth Banach space (with Fréchet differential norm), then $J$ is single-valued and continuous.

(ii) $J$ is uniformly continuous on every bounded set of a uniformly smooth Banach space.

(iii) If $X$ is a reflexive, smooth and strictly convex Banach space, $J^{*}: X^{*} \rightarrow X$ is the duality mapping of $X^{*}$, then $J^{-1}=J^{*}, J J^{*}=I_{X^{*}}, J^{*} J=I_{X}$.

Let $X$ be a smooth Banach space and $K$ be a nonempty, closed and convex subset of $X$. The function $\phi: X \times X \rightarrow R$ is defined by

$$
\phi(y, x)=\|y\|^{2}-2\langle y, J x\rangle+\|x\|^{2}
$$

for all $x, y \in X$.

Next, we recall the concept of the generalized $f$-projector operator, together with its properties. Let $G: K \times X^{*} \rightarrow R \cup\{+\infty\}$ be a functional defined as follows:

$$
G(\xi, \varphi)=\|\xi\|^{2}-2\langle\xi, \varphi\rangle+\|\varphi\|^{2}+2 \rho f(\xi),
$$

where $\xi \in K, \varphi \in X^{*}, \rho$ is a positive number and $f: K \rightarrow R \cup\{+\infty\}$ is proper, convex, and lower semicontinuous.

From the definitions of $G$ and $f$, it is easy to have the following properties:

(i) $G(\xi, \varphi)$ is convex and continuous with respect to $\varphi$ when $\xi$ is fixed;

(ii) $G(\xi, \varphi)$ is convex and lower semicontinuous with respect to $\xi$ when $\varphi$ is fixed.

Definition 2.1. Let $X$ be a real smooth Banach space and $K$ be a nonempty, closed and convex subset of $X$. We say that $\Pi_{K}^{f}: X \rightarrow 2^{K}$ is a generalized $f$-projection operator if

$$
\Pi_{K}^{f} x=\left\{u \in K: G(u, J x)=\inf _{\xi \in K} G(\xi, J x)\right\}, \quad \forall x \in X .
$$

In order to obtain our results, the following lemmas are crucial to us.

Lemma 2.2 (see [15]). Let $X$ be a real Banach space and $f: X \rightarrow R \cup\{+\infty\}$ be a lower semicontinuous convex functional. Then there exist $x^{*} \in X^{*}$ and $\alpha \in R$ such that

$$
f(x) \geq\left\langle x, x^{*}\right\rangle+\alpha, \quad \forall x \in X
$$


Lemma 2.3 (see [16]). Let $X$ be a uniformly convex and smooth Banach space and let $\left\{y_{n}\right\},\left\{z_{n}\right\}$ be two sequences of $X$. If $\phi\left(y_{n}, z_{n}\right) \rightarrow 0$ and either $\left\{y_{n}\right\}$ or $\left\{z_{n}\right\}$ is bounded, then $y_{n}-z_{n} \rightarrow 0$.

Let $K$ be a closed subset of a real Banach space $X$, and let $T$ be a mapping from $K$ to $K$. We denote by $F(T)$ the set of all fixed points of $T$. A point $p$ in $K$ is said to be an asymptotic fixed point of $T$, if $K$ contains a sequence $\left\{x_{n}\right\}$ which converges weakly to $p$ such that $\lim _{n \rightarrow \infty}\left(x_{n}-T x_{n}\right)=0$. The set of all asymptotic fixed points of $T$ will be denoted by $\widehat{F}(T)$. $T$ is called nonexpansive if $\|T x-T y\| \leq\|x-y\|$ for all $x, y \in K$, and relatively nonexpansive if $\widehat{F}(T)=F(T)$ and $\phi(p, T x) \leq \phi(p, x)$ for all $x \in K$ and $p \in F(T)$. Obviously, the definition of relatively nonexpansive mapping $T$ is equivalent to $\widehat{F}(T)=F(T)$ and $G(p, J T x) \leq G(p, J x)$ for all $x \in K$ and $p \in F(T)$.

Lemma 2.4 (see [17]). Let $X$ be a strictly convex and smooth Banach space, let $K$ be a closed, and convex subset of $X$, and let $T$ be a relatively nonexpansive mapping from $K$ into itself. Then $F(T)$ is closed, and convex.

Lemma 2.5 (see[10]). Let $X$ be a real reflexive and smooth Banach space and let $K$ be a nonempty, closed, and convex subset of X. The following statements hold:

(i) $\Pi_{K}^{f} x$ is a nonempty, closed, and convex subset of $K$ for all $x \in X$;

(ii) for all $x \in X, \widehat{x} \in \Pi_{K}^{f} x$ if and only if

$$
\langle\widehat{x}-y, J x-J \widehat{x}\rangle+\rho f(y)-\rho f(\widehat{x}) \geq 0, \quad \forall y \in K
$$

(iii) if $X$ is strictly convex, then $\Pi_{K}^{f}$ is a single-valued mapping.

Lemma 2.6 (see [10]). Let $X$ be a real reflexive and smooth Banach space, let $K$ be a nonempty, closed, and convex subset of $X$, and let $x \in X, \widehat{x} \in \Pi_{K}^{f} x$. Then

$$
\phi(y, \widehat{x})+G(\widehat{x}, J x) \leq G(y, J x), \quad \forall y \in K .
$$

Lemma 2.7 (see [10]). Let $X$ be a Banach space and $y \in X$. Let $f: X \rightarrow R \cup\{+\infty\}$ be a proper, convex and lower semicontinuous functional with convex domain $D(f)$. If $\left\{x_{n}\right\}$ is a sequence in $D(f)$ such that $x_{n} \rightarrow \widehat{x} \in \operatorname{int}(D(f))$ and $\lim _{n \rightarrow \infty} G\left(x_{n}, J y\right)=G(\widehat{x}, J y)$, then $\lim _{n \rightarrow \infty}\left\|x_{n}\right\|=\|\widehat{x}\|$.

Let $M$ be a closed and convex subset of a real Banach space $X$ and $g: M \times M \rightarrow R$ be a bifunction. The equilibrium problem for $g$ is as follows. Find $\widehat{x} \in M$ such that

$$
g(\widehat{x}, y) \geq 0, \quad \forall y \in M
$$

The set of all solutions for the above equilibrium problem is denoted by $\operatorname{EP}(g)$. For solving the equilibrium problem, one always assumes that the bifunction $g$ satisfies the following conditions:

(A1) $g(x, x)=0$, for all $x \in M$;

(A2) $g$ is monotone, that is, $g(x, y)+g(y, x) \leq 0$, for all $x, y \in M$; 
(A3) for all $x, y, z \in M, \lim \sup _{t \downarrow 0} g(t z+(1-t) x, y) \leqslant g(x, y)$;

(A4) for all $x \in M, g(x, \cdot)$ is convex and lower semicontinuous.

In order to prove our results, we present several necessary lemmas.

Lemma 2.8 (see [14]). Let $M$ be a closed and convex subset of a uniformly smooth, strictly convex and reflexive Banach space $X$, and $g(\cdot, \cdot)$ be a bifunction from $M \times M \rightarrow R$ satisfying the conditions (A1)-(A4). For all $r>0$ and $x \in X$, define the mappingas follows.

$$
T_{r} x=\left\{z \in M: g(z, y)+\frac{1}{r}\langle J z-J x, y-z\rangle \geq 0, \forall y \in M\right\}
$$

Then, the following statements hold:

(B1) $T_{r}$ is single-valued;

(B2) $T_{r}$ is a firmly nonexpansive-type mapping, that is, for all $x, y \in X$,

$$
\left\langle J T_{r} x-J T_{r} y, T_{r} x-T_{r} y\right\rangle \leq\left\langle J x-J y, T_{r} x-T_{r} y\right\rangle
$$

(B3) $F\left(T_{r}\right)=\widehat{F}\left(T_{r}\right)=\mathrm{EP}(g)$;

(B4) $\mathrm{EP}(g)$ is closed and convex.

Lemma 2.9 (see [14]). Let $M$ be a closed and convex subset of a smooth, strictly convex, and reflexive Banach space $X, g$ be a bifunction from $M \times M$ to $R$ satisfying the conditions (A1)-(A4), and $r>0$. Then, for any $x \in X$ and $q \in F\left(T_{r}\right)$,

$$
\phi\left(q, T_{r} x\right)+\phi\left(T_{r} x, x\right) \leq \phi(q, x) .
$$

\section{The Main Result}

In this section, we prove a strong convergence theorem for relatively nonexpansive mappings and equilibrium problems in Banach spaces.

Theorem 3.1. Let $X$ be a uniformly convex and uniformly smooth Banach space, $K$ and $M$ be two nonempty, closed and convex subsets of $X$ such that $K \cap M \neq \emptyset$. Let $T: K \rightarrow K$ be a relatively nonexpansive mapping and $f: X \rightarrow R$ a convex and lower semicontinuous mapping with $K \subset$ $\operatorname{int}(D(f))$. Let $g(\cdot, \cdot)$ be a bifunction from $M \times M \rightarrow R$, which satisfies the conditions (A1)-(A4). 
Assume that $\left\{\alpha_{n}\right\}_{n=0}^{\infty}$ is a sequence in $[0,1)$ such that $\lim _{\sup _{n \rightarrow \infty}} \alpha_{n}<1$, and $\left\{r_{n}\right\} \subset[a, \infty)$ for some $a>0$. Define a sequence $\left\{x_{n}\right\}$ in $K \cap M$ by the following algorithm:

$$
\begin{gathered}
x_{0}=x \in K \cap M, \quad H_{0}=K \cap M, \\
y_{n}=J^{-1}\left(\alpha_{n} J x_{n}+\left(1-\alpha_{n}\right) J T x_{n}\right), \\
u_{n} \in M \text { such that } g\left(u_{n}, y\right)+\frac{1}{r_{n}}\left\langle J u_{n}-J y_{n}, y-u_{n}\right\rangle \geq 0, \quad \forall y \in M, \\
H_{n+1}=\left\{z \in H_{n}: G\left(z, J u_{n}\right) \leq G\left(z, J y_{n}\right) \leq G\left(z, J x_{n}\right)\right\}, \\
x_{n+1}=\prod_{H_{n+1}}^{f} x, \quad n=0,1,2, \ldots
\end{gathered}
$$

If $F=F(T) \cap \mathrm{EP}(g)$ is nonempty, then $\left\{x_{n}\right\}$ converges strongly to $\Pi_{F}^{f} x$.

Proof. The proof is divided into the following four steps. all $n \geq 0$.

(I) First, we prove the following conclusion: $H_{n}$ is a closed convex set and $F \subset H_{n}$ for

It is obvious that $H_{0}$ is a closed convex set and $F \subset H_{0}$. Thus, we only need to show that $H_{n}$ is a closed convex set and $F \subset H_{n}$ for all $n \geq 1$.

Since $G\left(z, J u_{n}\right) \leq G\left(z, J y_{n}\right)$ and $G\left(z, J y_{n}\right) \leq G\left(z, J x_{n}\right)$ are respectively equivalent to

$$
\begin{aligned}
& 2\left\langle z, J y_{n}-J u_{n}\right\rangle+\left\|u_{n}\right\|^{2}-\left\|y_{n}\right\|^{2} \leq 0 \\
& 2\left\langle z, J x_{n}-J y_{n}\right\rangle+\left\|y_{n}\right\|^{2}-\left\|x_{n}\right\|^{2} \leq 0
\end{aligned}
$$

it follows that $H_{n+1}$ is closed and convex for all $n \geq 0$. Thus, we know that $\left\{x_{n}\right\}$ is well defined. Further, for any $u \in F$ and $n \geq 0$, we have

$$
\begin{aligned}
G\left(u, J y_{n}\right) \\
=\|u\|^{2}-2\left\langle u, \alpha_{n} J x_{n}+\left(1-\alpha_{n}\right) J T x_{n}\right\rangle+\left\|\alpha_{n} J x_{n}+\left(1-\alpha_{n}\right) J T x_{n}\right\|^{2}+2 \rho f(u) \\
\leq\|u\|^{2}-2 \alpha_{n}\left\langle u, J x_{n}\right\rangle-2\left(1-\alpha_{n}\right)\left\langle u, J T x_{n}\right\rangle+\alpha_{n}\left\|x_{n}\right\|^{2}+\left(1-\alpha_{n}\right)\left\|T x_{n}\right\|^{2}+2 \rho f(u) \\
=\alpha_{n}\left(\|u\|^{2}-2\left\langle u, J x_{n}\right\rangle+\left\|x_{n}\right\|^{2}+2 \rho f(u)\right) \\
\quad+\left(1-\alpha_{n}\right)\left(\|u\|^{2}-2\left\langle u, J T x_{n}\right\rangle+\left\|T x_{n}\right\|^{2}+2 \rho f(u)\right) \\
=\alpha_{n} G\left(u, J x_{n}\right)+\left(1-\alpha_{n}\right) G\left(u, J T x_{n}\right) \\
\leq G\left(u, J x_{n}\right) .
\end{aligned}
$$

On the other hand, it follows from the definition of $\left\{u_{n}\right\}$ and Lemma 2.8 that $u_{n}=T_{r_{n}} y_{n}$. From Lemma 2.9, we obtain

$$
\phi\left(u, u_{n}\right)=\phi\left(u, T_{r_{n}} y_{n}\right) \leq \phi\left(u, y_{n}\right)
$$


which implies that

$$
G\left(u, J u_{n}\right) \leq G\left(u, J y_{n}\right)
$$

Therefore, $u \in H_{n+1}$ for all $n \geq 0$.

(II) Second, we show that $\left\{x_{n}\right\}$ is bounded and $\lim _{n \rightarrow \infty} G\left(x_{n}, J x\right)$ exists.

Since $f: X \rightarrow R$ is a convex and lower semicontinuous mapping, a direct application of Lemma 2.2 yields that there exist $x^{*} \in X^{*}$ and $\alpha \in R$ such that

$$
f(y) \geq\left\langle y, x^{*}\right\rangle+\alpha, \quad \forall y \in X
$$

It follows that

$$
\begin{aligned}
G\left(x_{n}, J x\right) & =\left\|x_{n}\right\|^{2}-2\left\langle x_{n}, J x\right\rangle+\|x\|^{2}+2 \rho f\left(x_{n}\right) \\
& \geq\left\|x_{n}\right\|^{2}-2\left\langle x_{n}, J x\right\rangle+\|x\|^{2}+2 \rho\left\langle x_{n}, x^{*}\right\rangle+2 \rho \alpha \\
& =\left\|x_{n}\right\|^{2}-2\left\langle x_{n}, J x-\rho x^{*}\right\rangle+\|x\|^{2}+2 \rho \alpha \\
& \geq\left\|x_{n}\right\|^{2}-2\left\|J x-\rho x^{*}\right\|\left\|x_{n}\right\|+\|x\|^{2}+2 \rho \alpha \\
& =\left(\left\|x_{n}\right\|-\left\|J x-\rho x^{*}\right\|\right)^{2}+\|x\|^{2}-\left\|J x-\rho x^{*}\right\|^{2}+2 \rho \alpha .
\end{aligned}
$$

Since $x_{n}=\Pi_{H_{n}}^{f} x$, it follows from (3.7) that

$$
\begin{aligned}
G(u, J x) & \geq G\left(x_{n}, J x\right) \\
& \geq\left(\left\|x_{n}\right\|-\left\|J x-\rho x^{*}\right\|\right)^{2}+\|x\|^{2}-\left\|J x-\rho x^{*}\right\|^{2}+2 \rho \alpha, \quad \forall u \in F,
\end{aligned}
$$

which implies that $\left\{x_{n}\right\}$ is bounded and so is $\left\{G\left(x_{n}, J x\right)\right\}$. By the fact that $x_{n+1} \in H_{n+1} \subset H_{n}$ and Lemma 2.6, we obtain

$$
\phi\left(x_{n+1}, x_{n}\right)+G\left(x_{n}, J x\right) \leq G\left(x_{n+1}, J x\right) .
$$

It is obvious that

$$
\phi\left(x_{n+1}, x_{n}\right) \geq\left(\left\|x_{n+1}\right\|-\left\|x_{n}\right\|\right)^{2} \geq 0
$$

and so $\left\{G\left(x_{n}, J x\right)\right\}$ is nondecreasing. Therefore, we know that $\lim _{n \rightarrow \infty} G\left(x_{n}, J x\right)$ exists.

(III) Third, we prove that, if $x_{n_{k}} \rightarrow \widehat{x}$, then $\widehat{x} \in F$, where $\left\{x_{n_{k}}\right\}$ is an arbitrarily weakly convergent subsequence of $\left\{x_{n}\right\}$.

It follows from the definition of $H_{n+1}$ and $x_{n+1} \in H_{n}$ that

$$
\phi\left(x_{n+1}, u_{n}\right) \leq \phi\left(x_{n+1}, y_{n}\right) \leq \phi\left(x_{n+1}, x_{n}\right) \leq G\left(x_{n+1}, J x\right)-G\left(x_{n}, J x\right) .
$$


Taking $\lim _{n \rightarrow \infty}$ in (3.11), we get

$$
\lim _{n \rightarrow \infty} \phi\left(x_{n+1}, u_{n}\right)=\lim _{n \rightarrow \infty} \phi\left(x_{n+1}, y_{n}\right)=\lim _{n \rightarrow \infty} \phi\left(x_{n+1}, x_{n}\right)=0
$$

Applying Lemma 2.3, we obtain

$$
\lim _{n \rightarrow \infty}\left\|x_{n+1}-u_{n}\right\|=\lim _{n \rightarrow \infty}\left\|x_{n+1}-y_{n}\right\|=\lim _{n \rightarrow \infty}\left\|x_{n+1}-x_{n}\right\|=0
$$

Next, we show that $\widehat{x} \in \widehat{F}(T)=F(T)$.

From the fact that $J$ is uniformly norm-to-norm continuous on bounded sets, we have

$$
\lim _{n \rightarrow \infty}\left\|J x_{n+1}-J y_{n}\right\|=\lim _{n \rightarrow \infty}\left\|J x_{n+1}-J x_{n}\right\|=0 .
$$

Note that

$$
\begin{aligned}
\left\|J x_{n+1}-J y_{n}\right\| & =\left\|J x_{n+1}-\alpha_{n} J x_{n}-\left(1-\alpha_{n}\right) J T x_{n}\right\| \\
& =\left\|\left(1-\alpha_{n}\right) J x_{n+1}-\left(1-\alpha_{n}\right) J T x_{n}+\alpha_{n} J x_{n+1}-\alpha_{n} J x_{n}\right\| \\
& \geq\left(1-\alpha_{n}\right)\left\|J x_{n+1}-J T x_{n}\right\|-\alpha_{n}\left\|J x_{n+1}-J x_{n}\right\|
\end{aligned}
$$

and thus

$$
\begin{aligned}
\left\|J x_{n+1}-J T x_{n}\right\| & \leq \frac{1}{1-\alpha_{n}}\left\|J x_{n+1}-J y_{n}\right\|+\frac{\alpha_{n}}{1-\alpha_{n}}\left\|J x_{n+1}-J x_{n}\right\| \\
& \leq \frac{1}{1-\alpha_{n}}\left(\left\|J x_{n+1}-J y_{n}\right\|+\left\|J x_{n+1}-J x_{n}\right\|\right) .
\end{aligned}
$$

From (3.14) and $\lim \sup _{n \rightarrow \infty} \alpha_{n}<1$, we get

$$
\lim _{n \rightarrow \infty}\left\|J x_{n+1}-J T x_{n}\right\|=0
$$

Since $J^{-1}$ is uniformly norm-to-norm continuous on bounded sets, we have

$$
\lim _{n \rightarrow \infty}\left\|x_{n+1}-T x_{n}\right\|=0
$$

Since

$$
\begin{aligned}
\left\|x_{n}-T x_{n}\right\| & =\left\|x_{n}-x_{n+1}+x_{n+1}-T x_{n}\right\| \\
& \leq\left\|x_{n}-x_{n+1}\right\|+\left\|x_{n+1}-T x_{n}\right\|,
\end{aligned}
$$


we have

$$
\lim _{n \rightarrow \infty}\left\|x_{n}-T x_{n}\right\|=\lim _{k \rightarrow \infty}\left\|x_{n_{k}}-T x_{n_{k}}\right\|=0
$$

and so

$$
\widehat{x} \in \widehat{F}(T)=F(T)
$$

Now, we show $\widehat{x} \in \operatorname{EP}(g)$. Since

$$
\left\|u_{n}-y_{n}\right\| \leq\left\|x_{n+1}-u_{n}\right\|+\left\|x_{n+1}-y_{n}\right\|
$$

we get

$$
\lim _{n \rightarrow \infty}\left\|u_{n}-y_{n}\right\|=0
$$

Since $J$ is a uniformly norm-to-norm continuous on bounded sets, we have

$$
\lim _{n \rightarrow \infty}\left\|J u_{n}-J y_{n}\right\|=0
$$

From the assumption that $r_{n} \geq a$, we get

$$
\lim _{n \rightarrow \infty} \frac{\left\|J u_{n}-J y_{n}\right\|}{r_{n}}=0
$$

It follows from $u_{n}=T_{r_{n}} y_{n}$ that

$$
g\left(u_{n}, y\right)+\frac{1}{r_{n}}\left\langle J u_{n}-J y_{n}, y-u_{n}\right\rangle \geq 0, \quad \forall y \in M
$$

From (A2), we obtain

$$
\left\|y-u_{n}\right\| \cdot \frac{\left\|J u_{n}-J y_{n}\right\|}{r_{n}} \geq \frac{1}{r_{n}}\left\langle J u_{n}-J y_{n}, y-u_{n}\right\rangle \geq-g\left(u_{n}, y\right) \geq g\left(y, u_{n}\right), \quad \forall y \in M
$$

Since $\lim _{n \rightarrow \infty}\left\|x_{n+1}-u_{n}\right\|=\lim _{n \rightarrow \infty}\left\|x_{n+1}-x_{n}\right\|=0$, we obtain

$$
\lim _{n \rightarrow \infty}\left\|x_{n}-u_{n}\right\|=\lim _{k \rightarrow \infty}\left\|x_{n_{k}}-u_{n_{k}}\right\|=0
$$


For any $h \in X^{*}$, it follows that

$$
\lim _{k \rightarrow \infty}\left(h\left(u_{n_{k}}\right)-h(\widehat{x})\right)=\lim _{k \rightarrow \infty}\left[h\left(u_{n_{k}}-x_{n_{k}}\right)+h\left(x_{n_{k}}-\widehat{x}\right)\right]=0
$$

and so $u_{n_{k}} \rightarrow \hat{x}$. From (3.27) and (A4), we know that

$$
g(y, \widehat{x}) \leq \liminf _{k \rightarrow \infty} g\left(y, u_{n_{k}}\right) \leq \lim _{k \rightarrow \infty}\left\|y-u_{n_{k}}\right\| \cdot \frac{\left\|J u_{n_{k}}-J y_{n_{k}}\right\|}{r_{n_{k}}}=0, \quad \forall y \in M .
$$

Letting

$$
y_{t}=t y+(1-t) \widehat{x} \in M, \quad \forall 0<t<1, y \in M,
$$

we have

$$
g\left(y_{t}, \widehat{x}\right) \leq 0
$$

It follows from (A1) that

$$
0=g\left(y_{t}, y_{t}\right) \leq \operatorname{tg}\left(y_{t}, y\right)+(1-t) g\left(y_{t}, \widehat{x}\right) \leq \operatorname{tg}\left(y_{t}, y\right)
$$

and thus

$$
g\left(y_{t}, y\right) \geq 0
$$

Taking the limit as $t \downarrow 0$ in (3.34) and from (A3), we have

$$
g(\widehat{x}, y) \geq 0, \quad \forall y \in M
$$

and so $\widehat{x} \in \mathrm{EP}(g)$.

(IV) Last, we prove that $x_{n} \rightarrow \Pi_{F}^{f} x$.

Since $F$ is a closed convex set, from Lemma 2.5, we know that $\Pi_{F}^{f} x$ is single-valued and denote that $w=\Pi_{F}^{f} x$. Since $x_{n}=\Pi_{H_{n}}^{f} x$ and $w \in F \subset H_{n}$, we have

$$
G\left(x_{n}, J x\right) \leq G(w, J x), \quad \forall n \geq 1 .
$$

For each given $x, G(\xi, J x)$ is convex and lower semicontinuous with respect to $\xi$, it is easy to see that $G(\xi, J x)$ is weakly lower semicontinuous with respect to $\xi$ and so

$$
G(\widehat{x}, J x) \leq \liminf _{k \rightarrow \infty} G\left(x_{n_{k}}, J x\right) \leq \limsup _{k \rightarrow \infty} G\left(x_{n_{k}}, J x\right) \leq G(w, J x) .
$$


From the definition of $\Pi_{F}^{f} x$ and $\widehat{x} \in F$, we know that $\widehat{x}=w$ and so $\lim _{k \rightarrow \infty} G\left(x_{n_{k}}, J x\right)=$ $G(\widehat{x}, J x)$. It follows from Lemma 2.7 that $\lim _{k \rightarrow \infty}\left\|x_{n_{k}}\right\|=\|\widehat{x}\|$. The Kadec-Klee property of $X$ implies that $\left\{x_{n_{k}}\right\}$ converges strongly to $\Pi_{F}^{f} x$. Since $\left\{x_{n_{k}}\right\}$ is an arbitrarily weakly convergent sequence of $\left\{x_{n}\right\}$, we conclude that $\left\{x_{n}\right\}$ converges strongly to $\Pi_{F}^{f} x$. This completes the proof.

Remark 3.2. Letting $M=X, \operatorname{EP}(g)=X$ and $u_{n}=y_{n}$ in (3.1), then $H_{n+1}=\left\{z \in H_{n}: G\left(z, J y_{n}\right) \leq\right.$ $\left.G\left(z, J x_{n}\right)\right\}$ and so Theorem 3.1 reduces to Theorem 4.1 of Li et al. [10].

\section{Acknowledgments}

This work was supported by the Key Program of NSFC (Grant no. 70831005) and the National Natural Science Foundation of China $(11171237,11101069)$. The work is also supported by HK CityU, CTTFS (9360142).

\section{References}

[1] Y. Alber, "Generalized projection operators in Banach spaces: properties and applications," in Proceedings of the Israel Seminar, vol. 1 of Functional Differential Equation, pp. 1-21, Ariel, Israel, 1994.

[2] J. Li, "The generalized projection operator on reflexive Banach spaces and its applications," Journal of Mathematical Analysis and Applications, vol. 306, no. 1, pp. 55-71, 2005.

[3] K.-q. Wu and N.-j. Huang, "The generalised $f$-projection operator with an application," Bulletin of the Australian Mathematical Society, vol. 73, no. 2, pp. 307-317, 2006.

[4] K.-q. Wu and N.-j. Huang, "Properties of the generalized $f$-projection operator and its applications in Banach spaces," Computers \& Mathematics with Applications, vol. 54, no. 3, pp. 399-406, 2007.

[5] Y. Alber, "Metric and generalized projection operators in Banach spaces: properties and applications," in Theory and Applications of Nonlinear Operators of Accretive and Monotone Type, A. G. Kartsatos, Ed., vol. 178, pp. 15-50, Marcel Dekker, New York, NY, USA, 1996.

[6] Y. Alber, "Proximal projection methods for variational inequalities and Cesro averaged approximations," Computers \& Mathematics with Applications, vol. 43, no. 8-9, pp. 1107-1124, 2002.

[7] Y. Alber and S. Guerre-Delabriere, "On the projection methods for fixed point problems," Analysis, vol. 21, no. 1, pp. 17-39, 2001.

[8] K.-Q. Wu and N.-J. Huang, "The generalized $f$-projection operator and set-valued variational inequalities in Banach spaces," Nonlinear Analysis. Theory, Methods $\mathcal{E}$ Applications, vol. 71, no. 7-8, pp. 2481-2490, 2009.

[9] D. Butnariu, S. Reich, and A. J. Zaslavski, "Weak convergence of orbits of nonlinear operators in reflexive Banach spaces," Numerical Functional Analysis and Optimization, vol. 24, no. 5-6, pp. 489-508, 2003.

[10] X. Li, N.-j. Huang, and D. O'Regan, "Strong convergence theorems for relatively nonexpansive mappings in Banach spaces with applications," Computers $\mathcal{E}$ Mathematics with Applications, vol. 60, no. 5, pp. 1322-1331, 2010.

[11] E. Blum and W. Oettli, "From optimization and variational inequalities to equilibrium problems," The Mathematics Student, vol. 63, no. 1-4, pp. 123-145, 1994.

[12] P. L. Combettes and S. A. Hirstoaga, "Equilibrium programming in Hilbert spaces," Journal of Nonlinear and Convex Analysis, vol. 6, no. 1, pp. 117-136, 2005.

[13] X. Qin, S. Y. Cho, and S. M. Kang, "Strong convergence of shrinking projection methods for quasi- $\phi-$ nonexpansive mappings and equilibrium problems," Journal of Computational and Applied Mathematics, vol. 234, no. 3, pp. 750-760, 2010.

[14] W. Takahashi and K. Zembayashi, "Strong and weak convergence theorems for equilibrium problems and relatively nonexpansive mappings in Banach spaces," Nonlinear Analysis. Theory, Methods $\mathcal{E}$ Applications, vol. 70, no. 1, pp. 45-57, 2009.

[15] K. Deimling, Nonlinear Functional Analysis, Springer, Berlin, Germany, 1985. 
[16] S. Kamimura and W. Takahashi, "Strong convergence of a proximal-type algorithm in a Banach space," SIAM Journal on Optimization, vol. 13, no. 3, pp. 938-945, 2002.

[17] S.-y. Matsushita and W. Takahashi, "A strong convergence theorem for relatively nonexpansive mappings in a Banach space," Journal of Approximation Theory, vol. 134, no. 2, pp. 257-266, 2005. 


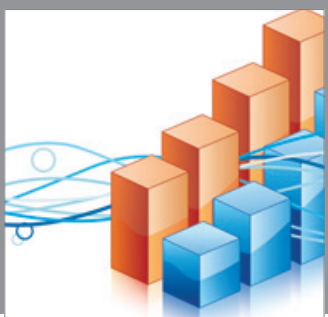

Advances in

Operations Research

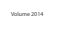

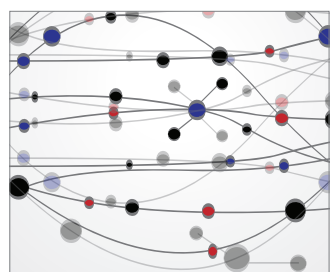

\section{The Scientific} World Journal
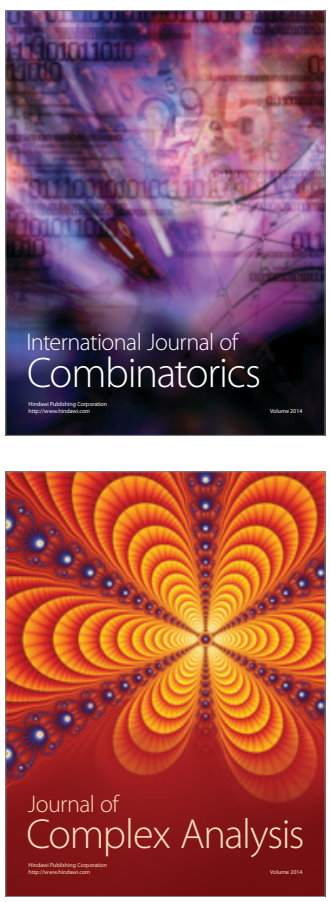

International Journal of

Mathematics and

Mathematical

Sciences
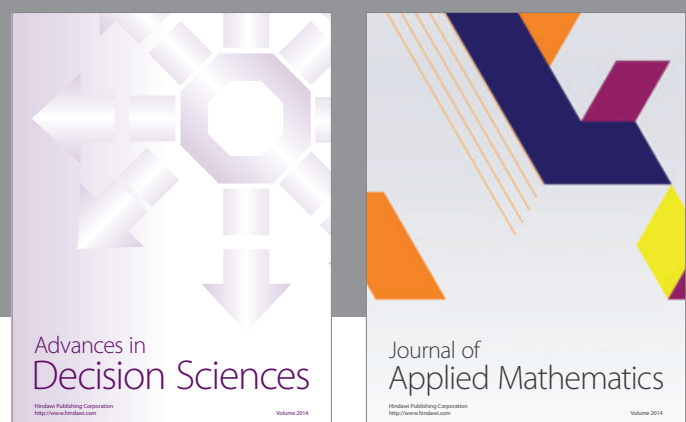

Journal of

Applied Mathematics
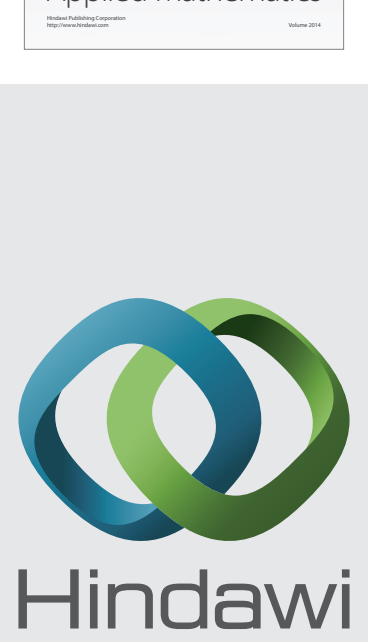

Submit your manuscripts at http://www.hindawi.com
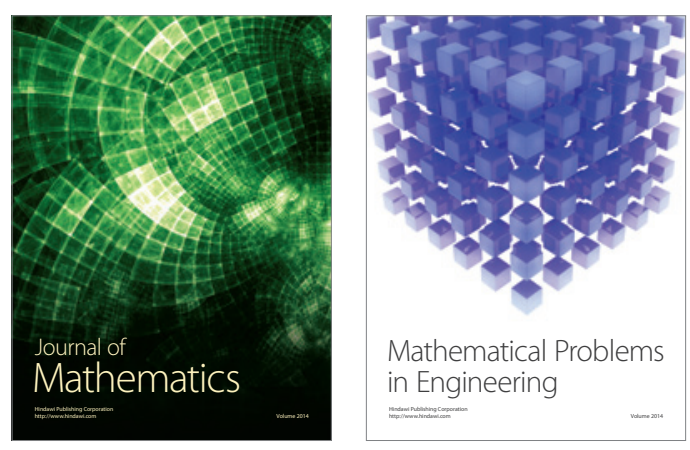

Mathematical Problems in Engineering
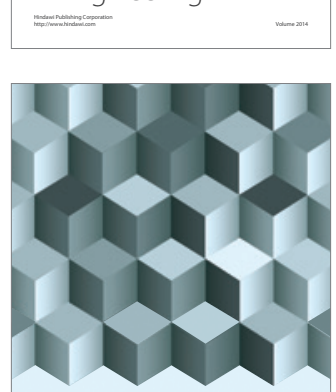

Journal of

Function Spaces
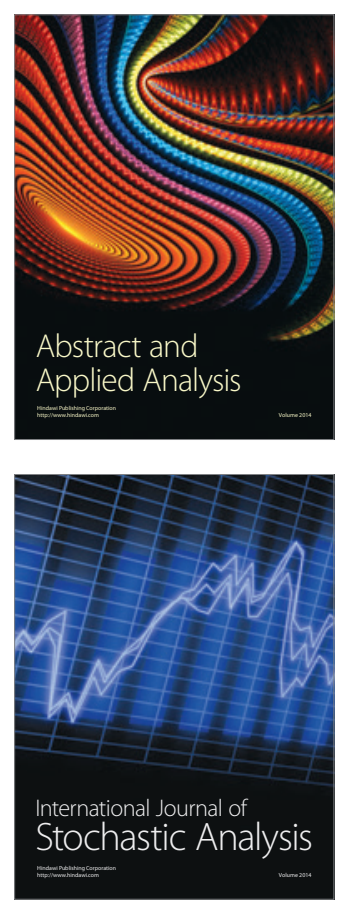

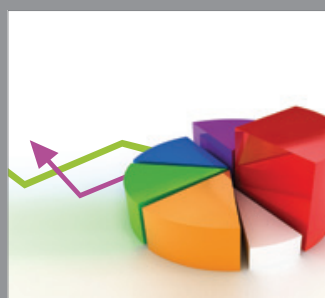

ournal of

Probability and Statistics

Promensencen
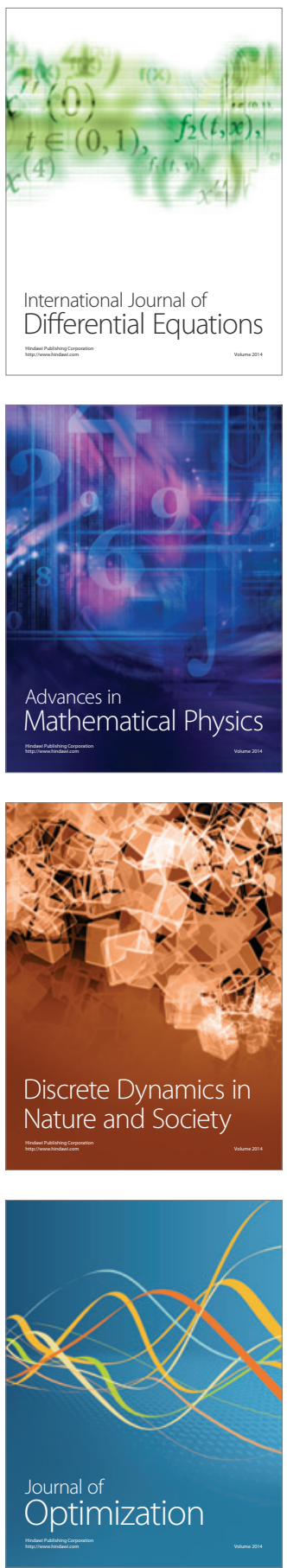